Nordisk MuseOlOgi $2002 \cdot 2$, s. 6I-65

\title{
The SPIral
}

\section{AS CONCEPT AND AS METAPHOR}

\section{David Anderson}

Professor Patrick Geddes, perhaps the greatest of the early city planners and museologists in the United Kingdom, was commissioned by the Carnegie Trust in 1903 to put forward proposals to develop Carnegie's home town, the City of Dunfermline. The report was inspired by a determination to infuse the whole city with the museum spirit, and museums with an awareness of the needs and interests of the ordinary inhabitants of the city. Geddes' proposals are of relevance principally because of his determination to seek alternatives to the museums he saw around him. "I have no faith in the educational value of the commonplace art museum with its metal masterpieces in a glass case and the smithy no where," he wrote. "This whole museum tradition, though still too largely in power, answers but to stamp-or scalp-collecting. Wherever real technical education is beginning, it centres on seeing and sharing the real work, and then applies the paper drawings and the collections of the old system to their right uses." He stressed that he was aiming to create not Utopia but Eu-topia.

In 1909 , at approximately the same time as Geddes laid out his proposals for Dunfermline, the V\&A expressed its own vision of itself in relation to society and its development, through its last major rebuilding programme. In its rationality and order, its hierarchies and classifications, it turned resolutely against the museological tradition of Geddes and other social reformers - a tradition of which the V\&A itself has intermittently been part. The debate between these conflicting museologi- cal traditions - both of them reaching back to the very origins of the Museum - is one to which the Spiral itself now contributes.

The Spiral will appear at a time when questions are once again being asked about the nature and purposes of museums, in a society which is less sure of its own goals and purposes than at any time in living memory. Nothing can be taken for granted. In his address to the ICOM Triennial Conference at the $\mathrm{Ha}$ gue in 1989, Professor Neil Postman asked 
62 his audience to imagine themselves in the Berlin of 1933 . What museum would they create? The museum that German society wanted at that time, or that which it needed? ${ }^{2}$ Perhaps Daniel Libeskind's Jewish Museum in Berlin is a belated answer to that question. To what question that faces our own society is the Spiral also the answer?

In this context it is significant that the Spiral has already been extensively represented as a metaphor by many people. First among these is Daniel Libeskind himself. He stresses that the Spiraldraws together art and history, the archaic and the new. It is an emblem which articulates V\&A's cross-cultural collections for a multicultural audience. Libeskind is well aware of the natural and physical scientific significance of the spiral form and also its classical and cultural references, from Archimedes' screw to the walls of Breughel's Tower of Babel, and from seashells to Escher's disorientating repetitions. For him, the spiral form both eases the savagery of the perpendicular and introduces new and centrifugal forces. The spiral brings with it a necessity for conflict and change in a way that the perpendicular does not. It describes the path of the tornado and the falling leaf.

Almost as frequently used by Libeskind is the metaphor of the Spiral as Ariadne's thread through the Labyrinth of the V\&A. For Libeskind, the V\&A is a secret city within a London which is itself, in Borges' words, the "Red Labyrinth." The experience of the visitor through this museum-city, bewildering in its diversity, is likened to a journey - itself a powerful metaphor. Cities are walked, lived, social spaces and are currently the subject of a rapidly growing art historical literature. They have quarters with distinctive cultures. In the secret city, the Spiral is the agora, the public square, the meeting point and the space for discourse and debate.

Both Libeskind, the Spiral's architect, and Cecil Balmond, its engineer, stress the classical sources of the structure, and the authenticity of its disorder. "Not for those early masters [the Greeks] the absolute fix of perfection" wrote Balmond. "Classical perfection was taken as a march of several orders, interdependent and bound, one within the other." For Balmond the building also represents Chaos, but he does not refer to another classical myth - that of Pandora's box - the disordering power of which might also aptly describe its creators' intentions. ${ }^{3}$

Libeskind is highly literate verbally as well as mathematically. His presentations are peppered with references to literary and oral traditions. He is narrator, author, calligrapher and critic - a creator of building as word.

The V\&A itself has described the Spiral as a key - one which unlocks the doors for visitors to its secret city of knowledge and experience. It is also a mirror held up to the city, with its changing light and activities reflected back on itself, inviting the institution to examine itself critically. The past is reflected in the future and the future in the past.

The fact that the Spiral has, even before it is built, acquired such diverse symbolic and mythic significance is an indication of a characteristic which appeals to some and offends others - its universality. The Spiral is, above all, an enabling building in the way that great myths are enabling. Each listener invests the myth with his or her own meaning, and herein lies its power. The Spiral will be in a state of constant metamorphosis, responding year by year and generation by generation to the changing needs and preoccupations of its users. If, as is suggested here, buildings en- 
able and express a vision of the relationship between the institution and the society of which the institution is part, the Spiral is, in museological terms, a deliberately radical building. It stands in antithesis to the formal certainties of the V\&A's 1909 extension. It is not a building with a single purpose and meaning. But this does not mean it is without meaning, as some critics have alleged. Instead it offers a "third-space," a space of many meanings. The Spiral will provide an arena for debates that will explore the creative yet troubled society which the UK has become.

The Spiral will be suggestive, rather than definitive, reliant upon expertise rather than authority for its success. It is perhaps this enabling quality that most disturbs some critics. Significantly drawing on Biblical rather than Classical sources, the former editor of the London Times, William Rees Mogg, has already declared the Spiral to be "a disaster for the V\&A in particular and civilisation in general. ... We are all being invited to take a walk in the desert with the Devil." The cultural rootedness of the Spiral makes it difficult to sustain the charge that it lies outside "civilisation." It is rather precisely because the Spiral draws upon strong scientific, aesthetic and cross-cultural traditions that is a source of such anxiety for some conservative critics. This is a challenge from within.

A central theme of the Spiral is the democratisation of culture, in itself one of the contested and civilising traditions of the V\&A. As the architectural critic Raymund Ryan has noted, for Libeskind spirit is about somehow harnessing the powers of society to allow it to examine itself. Knowledge and expertise are not regarded as a fixed resource, to be passed from the Museum to the public, but rather a broader and collaboratively developed process of enquiry which enriches and is enriched by the work of the institution. According to Ryan, "If Paul Klee famously spoke of taking a line for a walk in order to draw, then Libeskind takes the world on an expedition, and an expedition which is characterised by its endless restlessness". 4

The Spiral also redefines the relationship between process and practice of art and design. In the early twentieth century the $\mathrm{Mu}$ seum distanced itself from engagement with practice, and allied itself with disengaged appreciation. The Spiral will reassert that art and design is a way of being as well as a way of acting, not a specific and limited domain but an important dimension of all human activities. The project makes a strong statement that if the Spiral is to be a creative space, it cannot separate product from process, producer from user, concept from consumption, the mundane from the transcendent, the intellectual from the sensory, the handmade from the industrial, the public from the private, the individual from the social, arts as object from arts as interpretation - but yet it will represent the distinctive natures of different collections and disciplines. If the Spiral represents a challenge to the traditional museum, it is in part because the project will re-unite elements which the Museum was first established in the mid nineteenth century to combine, but which were later separated. From this broad historical perspective, it is the V\&A of the early to late twentieth century, not the Spiral, which may represent the aberration.

One focus for the debate about the Spiral has been the concept of excellence. Some critics have expressed concern that some space in the building will be used for a purpose other than display of the finest examples of contemporary art, craft and design. This, they 
say, represents a betrayal of the purpose of the V\&A. Libeskind's building will endorse the concept of excellence, and of the value of excellent products, but will broaden the debate to argue also for excellence of process and excellence of experience on the part of the public. Libeskind frequently emphasises the importance of experience, arguing that "this proposal offers new kinds of experience eluding the closure that would categorise the Museums as 'ready made', rigidly defined or passively neutral." He also sees the Spiral as a place where visitors are "celebrated as participants in the sensory and intellectual experience." 5 The object is an essential part of this quality of experience, but not in itself sufficient. In taking his stand on quality of experience, Libeskind also has the support of recent research by Csikszentmihalyi, among others, on the exceptional significance - both in nature and extent - of the museum experience. $^{6}$

For Cecil Balmond, the structure of the Spiral is an essential precondition for the experience it can offer. He argues that it represents a subversion of the immobility, muteness and compartmentalisation of formal, modernist cubes, of the overpowering of inspiration by technology, of the containment of the cage. He urges us to acknowledge and embrace instead the irregular rhythms and diversity of the complex reality we see in the world around us; in doing so we will find in the Spiral characteristics that seed the complex and give starting points to an inner logic that is more intuitive. In place of structure as container, he offers structure as trace, as episode, as staccato or punctuation. With this redefinition as the catalyst, he proposes that within the Spiral juxtaposition, hybridity and the localised (qualities he suggests we should value) become natural rather than aberrant.

Central to Balmond's vision is the concept of the informal - a concept that has a powerful educational as well as structural resonance - just one example of the underlying philosophical integration and unity of the Spiral. For Balmond the informal is not something random and arbitrary, but is based rather on a series of shifting certainties. Force in structural terms is not linear but a minimum path through a field of potential, a path whose trajectory is based on moments of mutual cooperation. Where the informal is concerned there are no distinct rules, no fixed patterns to be copied blindly. The structured solutions that arise from the informal impart hidden energies to a building, and prompt improvisation on the part of those who use it. The informal acts as an agent of release. Again, the Spiral represents a thirdspace - neither formally structured nor lacking structure, but one that is diversely structured.

It is also a building in which the architecture - as at the Jewish Museum but in a different way - prompts an emotional response. For Libeskind, feeling and sensation are essential elements of the Museum experience.

In being designed in this way, the Spiral is providing a gateway to the V\&A's rich and distinctive resources of objects, expertise, networks and learning paths, for a wider audience than is possible in a more traditional museum. In a society which is experiencing rapid changes in work, leisure and education, the architecture and engineering of the Spiral deliberately and intuitively acknowledge and respond to these future needs.

Libeskind's building is also unashamedly idealistic. The Spiral is a utopian, transcendental form. Libeskind acknowledges his debt 
to Benoit Mandelbrot (the discoverer of the fractals, the infinitely variable mathematical forms which will inform the design of the Spiral's tiles) who said that "in the mind's eye, a fractal is a way of seeing infinity." In this respect, Libeskind sees the building as mediating not just between the V\&A and the world beyond, but also between the particular and earthbound and the universal and infinite - that interplay of movement through the horizontal and vertical which the Spiral form so powerfully represents.

These are the terms on which the Spiral's creators - Libeskind and Balmond and the staff within the V\&A with whom they are working - take their stand and by which they ask it to be judged. It is a revolutionary architectural form which employs radical engineering solutions. Its implications for the work of the Museum are correspondingly significant.

\section{Notes}

1. F.A. Bather, "The Museum and the Citizen", in Museumskunde, 1905, pp198-205
2. Neil Postman, "Extension of the Museum Concept", in Museums, Generators of Culture, International Council of Museums '89 Foundation, The Hague, 1991, pp 41-48

3. Cecil Balmond, "New Structure and the Informal", in Architectual Design, London, September/October 1997

4. Raymund Ryan, "Beyond Libeskind", in Archictual Review, November 1997

5. Daniel Libeskind, "The Victoria and Albert Museum Boilerhouse Extension", in Architectual Design, London, September/October 1997

6. Mihaly Csikszentmihalyi and Rick E. Robinson,, The Art of Seeing: An Interpretation of the Aesthetic Encounter, J. Paul Getty Museum and Getty Centre for Education in the Arts, Malibu, 1990

\section{David Anderson}

Director of Learning and Interpretation

Adr: Victoria and Albert Museum, South Kensington, London SW7 2RL England

Fax: +44207942 2193

E-mail:d.anderson@vam.ac.uk 
Spiral 1:100 model, aerial view of Spiral.

Model made 1998,

Photograph: Andrew

Putter 2002.

Spiral 1:100 model showing design for planning permission 1998. Model made 1998, Photograph: Andrew Putter 2002.
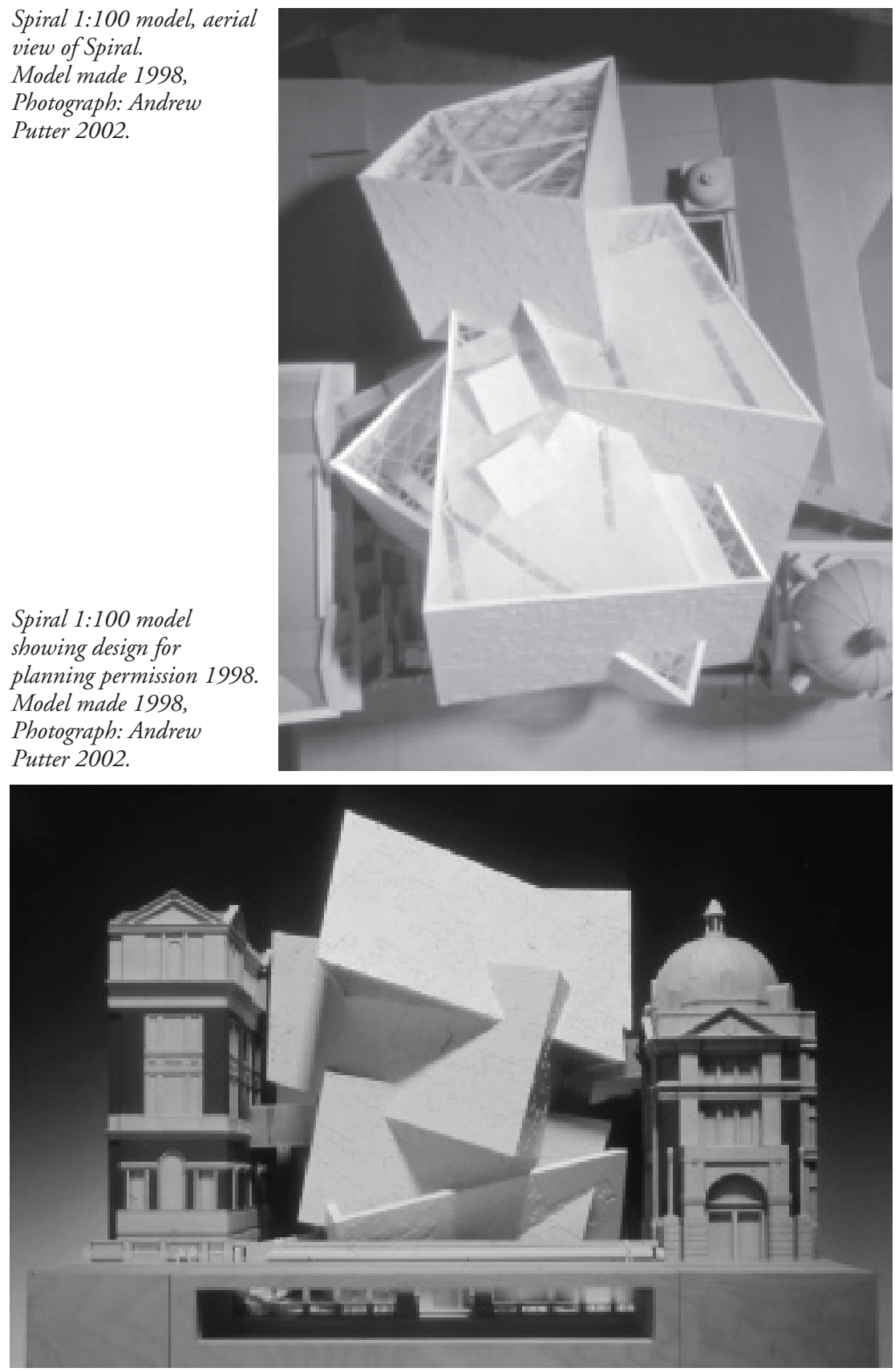